\title{
Limbic-Cortical-Ventral Striatal Activation during Retrieval of a Discrete Cocaine-Associated Stimulus: A Cellular Imaging Study with $\gamma$ Protein Kinase C Expression
}

\author{
Kerrie L. Thomas and Barry J. Everitt \\ Department of Experimental Psychology, University of Cambridge, Cambridge CB2 3EB, United Kingdom
}

We investigated the neuronal activation associated with reexposure to a discrete cocaine-associated stimulus using in situ hybridization to quantify the expression of the plasticityregulated gene, $\gamma$ protein kinase $\mathrm{C}(\gamma \mathrm{PKC})$, in the limbiccortical-ventral striatal system. Groups of rats were trained to self-administer cocaine paired with a light stimulus (Paired) or paired with an auditory stimulus but also receiving light presentations yoked to those in the Paired group (Unpaired). Additional groups received noncontingent cocaine-light pairings (Pavlovian) or saline-light pairings (Saline) that were yoked to the Paired group. After acquisition of self-administration by the Paired and Unpaired groups, all groups had a $3 \mathrm{~d}$ drug- and training-free period before being reexposed to noncontingent presentations of the light conditioning stimulus during a $5 \mathrm{~min}$ test session in the training context. There were four major patterns of results for regional $\gamma$ PKC expression $2 \mathrm{hr}$ later. (1)
Changes occurred only in groups in which the light was predictive of cocaine. (2) Increases were seen in the amygdala, but decreases were seen in the medial prefrontal cortex. (3) No changes were seen in the hippocampus. (4) Although changes were observed in the basal and central nuclei of the amygdala and the prelimbic cortex in both the Paired and Pavlovian groups, additional changes were observed in the nucleus accumbens core, lateral amygdala, and anterior cingulate cortex in the Pavlovian group. These results suggest not only that regionally selective alterations in $\gamma$ PKC expression are an index of the retrieval of Pavlovian associations formed between a drug and a discrete stimulus, but also that a distinct neural circuitry may underlie Pavlovian stimulus-reward associations in cocaine-experienced rats.

Key words: $\gamma$ protein kinase $C$; cocaine; memory retrieval; nucleus accumbens; frontal cortex; limbic system
Exposure to cocaine-paired environmental stimuli produces craving in cocaine-dependent humans (Gawin, 1991; Childress et al., 1993) that may contribute to relapse after abstinence (O'Brien et al., 1992). Brain imaging studies have reported increases in metabolic activity in several limbic regions in response to presentation of discrete cocaine-associated stimuli that were correlated with self-reports of craving for cocaine (Grant et al., 1996; Maas et al., 1998; Childress et al., 1999). These data suggest that Pavlovian learning mechanisms are critical to drug addiction. However, the neural circuitry and molecular substrates associated with these mechanisms are poorly understood (Berke and Hyman, 2000).

Both the formation of long-term memory and stimulus-cued retrieval of memories are dependent on new protein synthesis (Davis and Squire, 1984; Nader et al., 2000) and, in the case of exposure to cocaine cues, expression of the plasticity-associated gene $c$-fos (Brown et al., 1992; Crawford et al., 1995; Franklin and Druhan, 2000; Neisewander et al., 2000). However, c-fos expression may not be the optimal marker of neuronal activity. For example, $c$-fos induction is refractory to multiple psychostimulant challenges in some brain regions (Graybiel et al., 1990; Hope et al., 1994). Furthermore, in the hippocampus there is a dissocia-

Received Nov. 3, 2000; revised Dec. 20, 2000; accepted Jan. 16, 2001.

This work was supported by Medical Research Council (MRC) program Grant G9537855 and an MRC Cooperative in Brain, Behavior and Neuropsychiatry. We thank Simon R. Howes for technical assistance.

Correspondence should be addressed to Kerrie L. Thomas, Department of Experimental Psychology, University of Cambridge, Downing Street, Cambridge CB2 3EB, UK. E-mail: klt25@cus.cam.ac.uk.

Copyright (C) 2001 Society for Neuroscience 0270-6474/01/212526-10\$15.00/0 tion between the induction of the activity-dependent form of plasticity, long-term potentiation (LTP), and c-fos expression (Abraham et al., 1993; Worley et al., 1993). The expression and activity of the brain-specific $\gamma$ isoform of the intracellular serinethreonine protein kinase $\mathrm{C}(\gamma \mathrm{PKC})$ family, however, is highly correlated with learning (Van der Zee et al., 1992, 1997; Abeliovich et al., 1993a,b; Douma et al., 1998) and with hippocampal LTP (Thomas et al., 1994). $\gamma$ PKC is a brain-specific isoform of PKC that, unlike $c$-fos, is constitutively expressed in the majority of CNS neurons (Nishizuka, 1988; our unpublished observations), thus also allowing decreases in its expression to be quantified. These features indicate that studying $\gamma$ PKC expression provides a useful molecular tool with which to investigate the neural system that is activated during retrieval of cocaineassociated memories.

The dopaminergic mesolimbic pathway projecting from the ventral tegmental area (VTA) to the nucleus accumbens (NAcc) is widely accepted to be the critical substrate for the reinforcing effects of cocaine (Roberts et al., 1977; Wise and Bozarth, 1987). Dopamine itself may play a crucial role in learning associated with reinforcement within both the NAcc and other brain regions (Schultz and Dickinson, 2000). Glutamate-dependent plasticity processes in the NAcc, as well as in cortical areas providing the major glutamatergic innervation of the NAcc, namely regions of the medial prefrontal cortex (mPFC), the amygdala, and the hippocampus, have also been shown to be critical for learning in both aversive and appetitive settings (Morris et al., 1986; Miserendino et al., 1990; Burns et al., 1994; Kelley et al., 1997; Baldwin et al., 2000). Glutamate transmission in the NAcc is important in mediating cocaine-induced reinstatement of self-administration 
(SA) in rats (Cornish and Kalivas, 2000), suggesting that plasticity processes may also underlie drug-seeking behavior and may do so within a distributed corticolimbic-striatal system.

In this study, rats were trained to self-administer cocaine by responding on one of two levers; each drug infusion was accompanied by presentation of a light stimulus [conditioning stimulus (CS)] (Paired group). Using quantitative in situ hybridization, we measured the expression of $\gamma \mathrm{PKC}$ in response to presentation of this drug CS alone in the NAcc, VTA, and regions providing glutamatergic afferents to the NAcc. We were thus able to image the cellular neuroanatomical correlates of the motivational properties of a drug CS, including its ability to support drug-seeking behavior and reinstatement after extinction (Stewart et al., 1984; Arroyo et al., 1998). In addition to a Saline control group, two other important groups of rats were included in this study: (1) rats trained to self-administer cocaine, but for which light presentations were explicitly unpaired with drug (Unpaired group); and (2) rats receiving light-cocaine pairings, but in which the cocaine administration was not contingent on an instrumental response (Pavlovian group). These groups provided controls for the neuroadaptations that can accompany chronic cocaine exposure and the incentive properties of reward-associated stimuli. Guided by imaging studies of human cocaine abusers and our own studies of the neural basis of cue-controlled drug seeking in rats (Whitelaw et al., 1996; Weissenborn et al., 1997), we predicted changes in $\gamma$ PKC expression in limbic-cortical-ventral striatopallidal networks in response to presentation of the cocaine-associated CS.

\section{MATERIALS AND METHODS}

Animals. Male Lister hooded rats (300-400 gm; Charles River) were housed under a $12 \mathrm{hr}$ reverse light/dark cycle (lights off 9:00 A.M.). Experiments were performed between 10:00 A.M. and 4:00 P.M. Animals were maintained at $90 \%$ body weight by restricting food ( $20 \mathrm{gm} \mathrm{lab}$ chow daily), starting after surgery and continuing for the duration of the experiment. During the cocaine self-administration training period, the food was given to the rats once they had returned to their home cages after training. Water was available ad libitum in the home cages. The experiments were undertaken in accordance with the UK 1986 Animals (Scientific Procedures) Act (project license PPL 80/00684).

Intravenous catheterization. Rats were intraperitoneally anesthetized with $1 \mathrm{ml} / 100 \mathrm{gm}$ body weight Avertin (10 gm of 2,2,2-tribromoethanol; Sigma-Aldrich, Poole, UK) and $4.5 \mathrm{ml}$ of Dulbecco's "A" solution (5 mg of tertiary amyl alcohol in $4.5 \mathrm{ml}$ of PBS; Unipath Ltd.) in $40 \mathrm{ml}$ of absolute ethanol. Indwelling jugular catheters (manufactured in-house) were implanted, exiting between the scapulae [for details of catheter manufacture and surgery, see Caine et al. (1993)]. For the catheter construction, the silicone tubing (STHT-C-030 and STHT-C-020) was obtained from Osteotec Ltd., the stainless steel guide cannula (C313G 5UP) was obtained from Semat Technical Ltd., and the polypropylene mesh $(500 \mu \mathrm{m} \times 500 \mu \mathrm{m}$; Y-CMP-500-D) was purchased from Small Parts Inc. Before recovery, rats were given Timentin $(6.67 \mathrm{mg} / 0.1 \mathrm{ml}$ in sterile $0.9 \%$ saline, i.v.) and $5 \mathrm{ml}$ of sterile $0.5 \%$ glucose $/ 0.9 \%$ saline solution, intraperitoneally. Antibiotic treatment continued for 2 additional days [Timentin, $6.67 \mathrm{mg} / 0.1 \mathrm{ml}$ in heparinized $(30 \mathrm{U} / \mathrm{ml}) 0.9 \%$ sterile saline, i.v.]; thereafter catheter patency was maintained using daily intravenous infusions of $0.1 \mathrm{ml}$ of heparinized $(30 \mathrm{U} / \mathrm{ml}) 0.9 \%$ sterile saline (flushing). During self-administration training, the catheters were flushed both before and immediately after the training session. When not in use, the implanted catheters were capped externally with a short length of Tygon tubing (Altec 01-94-1554, Altevin Laboratory Ltd.), plugged with monofilament, and protected with a stainless steel cap.

Apparatus. Operant chambers $(24 \times 22 \times 20 \mathrm{~cm}$, Campden Instruments, Loughborough, UK) were housed in individual, ventilated soundand light-attenuated boxes. Each chamber was lit by a red $2.5 \mathrm{~W}, 24 \mathrm{~V}$ house light positioned centrally in the ceiling of the chamber. Two retractable levers $(3.8 \mathrm{~cm}$ wide, $5.5 \mathrm{~cm}$ from the grid floor, and $10 \mathrm{~cm}$ apart) were positioned on one $(22 \times 20 \mathrm{~cm})$ wall of the chamber. White $2.5 \mathrm{~W}, 24 \mathrm{~V}$ lights $(2 \mathrm{~cm})$ were positioned $2.8 \mathrm{~cm}$ above the levers, which could be illuminated to serve as a visual CS. In addition, a tone generator
Table 1. The design of experimental groups used

\begin{tabular}{|c|c|c|c|}
\hline Group & $\begin{array}{l}\text { Training } \\
\text { (context A) }\end{array}$ & $\begin{array}{l}\text { Testing } \\
\text { (context A) }\end{array}$ & $\begin{array}{l}\text { Association } \\
\text { examined } \\
\text { in testing }\end{array}$ \\
\hline Paired & $\mathrm{L} \rightarrow \mathrm{CS}_{1} \rightarrow$ cocaine & $\mathrm{CS}_{1} \rightarrow$ cocaine & $\begin{array}{l}\text { Pavlovian } \\
\text { CS-cocaine } \\
\text { Instrumental } \\
\text { CS-response }\end{array}$ \\
\hline Pavlovian & $\mathrm{L} \mapsto \mathrm{CS}_{1} \rightarrow$ cocaine & $\mathrm{CS}_{1} \rightarrow$ cocaine & $\begin{array}{l}\text { Pavlovian } \\
\text { CS-cocaine }\end{array}$ \\
\hline Unpaired & $\begin{array}{l}\mathrm{L} \rightarrow \mathrm{CS}_{1} \rightarrow \text { cocaine } \\
\mathrm{L} \rightarrow \mathrm{CS}_{2} \rightarrow \text { cocaine }\end{array}$ & $\mathrm{CS}_{1} \rightarrow$ cocaine & Familiar stimulus \\
\hline Saline & $\mathrm{L} \mapsto \mathrm{CS}_{1} \rightarrow$ cocaine & $\mathrm{CS}_{1} \rightarrow$ cocaine & Familiar stimulus \\
\hline
\end{tabular}

L, Discriminated level press; $\mathrm{CS}_{1}$, light stimulus; $\mathrm{CS}_{2}$, tone stimulus; $\rightarrow$, associated with; $\rightarrow$, is not associated with. $\mathrm{CS}_{1}$ is presented to all four experimental groups during training, whether contingent on an instrumental response or not.

(RS Components, Northants, UK) located in the ceiling to the left of the wall housing the levers was available to provide an auditory CS (see below). The external guide cannula of the implanted catheter on each rat was attached via a metal spring-protected plastic lead (Plastic One) to a ceiling-mounted, counter-balanced single-channel liquid swivel (Stoelting) that allowed the animal free movement within the operant chamber. Tygon plastic connected the swivel to an operant box-designated Razel infusion pump (Semat Technical Ltd.) situated outside the light-sound attenuating chamber from which (drug) solution was to be delivered.

Experimental groups. One group of rats was trained to self-administer cocaine intravenously; each instrumental lever press resulted in the presentation of a light stimulus and a single drug inf usion (Paired group) (Table 1). As Pavlovian associations form between a stimulus and a reinforcer, they begin to exert a motivational influence over the acquisition of instrumental actions to gain access to the reinforcer (Dickinson and Balleine, 1994). Any genomic responses to a noncontingent experimenter-controlled presentation of a cocaine-associated CS in the absence of drug might relate to associations formed between the following during training: (1) the stimulus and the drug, a purely Pavlovian association; (2) the stimulus and the instrumental response to gain reinforcer; and (3) the subsequent retrieval of the association of the action performed and the reinforcer. The latter two associations characterize instrumental learning (Balleine and Dickinson, 1998). Both Pavlovian and instrumental learning contribute to drug-seeking behavior. To dissociate possible regions inherent in processing Pavlovian stimulusdrug (stimulus-reinforcer) associations from those (stimulus-response and response-reinforcer) participating in instrumentally responding for cocaine, we included in our investigations a group of rats that had received behaviorally noncontingent stimulus-drug presentations (Pavlovian group). We predicted that those areas involved in learning Pavlovian stimulus-reward associations would be activated on the presentation of the conditioned cue. Moreover, in rats responding for drug, the CS would activate those areas that also may be involved with stimulusresponse associations. To control for molecular neuroadaptations that occur with repeated drug challenge (Nestler and Aghajanian, 1997), we trained a group of rats to self-administer cocaine in which the conditioned cue was an auditory tone. However, these rats received light stimulus presentations that were not paired with drug (Unpaired group). A final group received noncontingent saline infusions paired with the light stimulus (Saline group). The design of the experimental groups was such that, during training, the timing of cocaine or saline infusions for the Pavlovian and Saline groups was yoked to the master Paired group. In addition, light presentations in the Pavlovian, Unpaired, and Saline groups were time-locked to the Paired group. Therefore, the number and frequency of light presentations throughout training were identical in all experimental groups. During the test phase, the light stimulus was presented in the absence of a cocaine infusion and levers in the chambers.

Conditioning procedure and acquisition criteria. At least $7 \mathrm{~d}$ after recovery from catheter implantation, rats were trained to self-administer 0.1 $\mathrm{ml}$ of cocaine hydrochloride $(0.25 \mathrm{mg}$ of base per infusion, i.v., dissolved in $0.9 \%$ sterile saline; McFarlan-Smith). Rats were placed into the operant chambers and attached to the infusion pumps. The $2 \mathrm{hr}$ training 
session was initiated by the experimenter pressing rapidly three times on one of the two levers and thereby designating this lever as the active drug-delivering lever for the duration of the experiment for that rat. These initial depressions of the active lever did not result in a drug inf usion. The levers were randomly assigned as active and inactive drug levers but were left-right counter-balanced across the experimental group. Illumination of the red house light signaled the beginning of the training session, and rats were allowed to acquire intravenous cocaine self-administration under a continuous reinforcement schedule. Depression of the active lever by the rat resulted in the immediate extinction of the red house light and either a $20 \mathrm{sec}$ illumination of the white light directly above the active lever (Paired group; $n=18$ ) or a $20 \mathrm{sec}$ intermittent tone (Unpaired group; $n=6$ ). One second after active lever depression, both levers were retracted for $19 \mathrm{sec}$, and the pump concomitantly delivered a $3.6 \mathrm{sec}$ duration cocaine inf usion. The rats effectively received a $20 \mathrm{sec}$ time-out period in which neither lever and, consequently, no further cocaine inf usions were available before the extinction of the CS, red house light reillumination, and extension of both levers back into the operant chamber. Depression of the inactive lever had no programmed consequence. The Pavlovian group $(n=12)$ was exposed to the same number of light-cocaine infusion pairings yoked to the Paired group and therefore pairings were given at the same time, and resulted in identical time-out periods as the Paired group. Although the two levers were present in the operant chambers of the Pavlovian group, their depression had no consequence for the animal. The Saline rats were yoked to the Paired group in terms of white light stimulus presentation and time-out conditions, but rats of this group received an intravenous infusion of $0.1 \mathrm{ml}$ of sterile saline $(n=6)$. The two levers were present in the operant chambers of the Saline group, but their depression had no consequences for the animal. The number and time of depression of the levers were recorded throughout each training session. The Paired and Unpaired groups were given continuous daily training sessions until individual rats showed a highly discriminated lever pressing on the active lever when active-inactive lever presses reached a ratio of $>90 \%$ for three consecutive sessions. Training continued for rats in the Pavlovian and Saline groups that were yoked to rats in the Paired group in terms of CS presentations until their master Paired animals reached the discriminated lever-pressing criteria.

Lever-pressing data were analyzed by repeated measures. Violations of the sphericity assumption (Mauchly's test) within the repeated measures ANOVAs were corrected using the Huynh-Feldt $(\epsilon)$ df correction. Significant interactions were followed by post hoc analysis using Sidak's test for multiple comparisons.

Test phase. After the training criterion had been met, all rats then received a $3 \mathrm{~d}$ drug washout period in which they remained in their home cages and received no drug infusions. On the fourth day after conditioning, all rats were placed back in the training chambers. The levers in the chambers were not available to the animals. After $2 \mathrm{~min}$, rats were presented with five $1 \mathrm{sec}$ white light CS with an interstimulus interval of 90 sec. One minute after the last light CS exposure, the rats were transferred back to their home cages; $2 \mathrm{hr}$ later, they were killed by $\mathrm{CO}_{2}$ inhalation, and their brains were removed rapidly and frozen on dry ice. The $2 \mathrm{hr}$ test time point after the CS presentations was chosen on the basis of a previous study showing that maximal levels of mRNA for $\gamma$ PKC were measured $2 \mathrm{hr}$ after the induction of the activity-dependent form of plasticity, LTP, in the hippocampus (Thomas et al., 1994). The brains were stored at $-80^{\circ} \mathrm{C}$ until they were processed for in situ hybridization.

Tissue preparation, in situ hybridization, and grain density analysis. Cellular imaging studies have successfully investigated the genomic response to environments associated with cocaine administration using the expression of the immediate early gene $c$-fos as a marker for neuronal activation (Brown et al., 1992; Crawford et al., 1995; Franklin and Druhan, 2000; Neisewander et al., 2000). The use of c-Fos as a marker of cellular activation after exposure to cocaine-associated cues has some interpretational difficulties. First, c-fos expression in the NAcc exhibits tolerance with chronic cocaine administration (Graybiel et al., 1990; Hope et al., 1994). Second, c-Fos is not always a marker for cellular activation (Dragunow and Faull, 1989), particularly in the hippocampus (Abraham et al., 1993; Worley et al., 1993). We have seen more than fivefold increases in $\gamma$ PKC expression in the hippocampus in response to a context that was associated with mild footshock (K. L. Thomas, J. Hall, and B. J. Everitt, unpublished observations), suggesting that changes in $\gamma$ PKC expression can be measured in the hippocampus on retrieval of contextual memories. Third, the basal expression of $c$-fos in many brain regions is very low. Therefore, quantitative measures of alterations in expression not only are quite variable, but also do not permit the detection of potential decreases in regional activity.

Tissue sections $(14 \mu \mathrm{m})$ were cut at $-18^{\circ} \mathrm{C}$ on a freezing Microtome (Leica Instruments) and thaw-mounted onto poly-L-lysine $\mathrm{HBr}(0.02$ $\mathrm{mg} / \mathrm{ml}$ diethyl pyrocarbonate-treated water; molecular mass $>300,000$; Sigma)-coated glass slides. Sections at equivalent anteroposterior levels from different experimental groups were mounted onto the same slide. Each slide was mounted with sections from two or three individual rats from the Paired group. The sections were air-dried for not $<30 \mathrm{~min}$, fixed in $4 \%$ paraformaldehyde in $0.1 \mathrm{M}$ PBS, $\mathrm{pH} 7.4$, for $5 \mathrm{~min}$, rinsed in PBS for $1 \mathrm{~min}$, delipidated in $70 \%$ ethanol for $4 \mathrm{~min}$, and stored in $95 \%$ ethanol at $4^{\circ} \mathrm{C}$. A DNA antisense probe complementary to nucleotides 1157-1191 of the rat $\gamma$ PKC gene (Ono et al., 1988) was synthesized on an Applied Biosystems DNA synthesizer. The resulting oligonucleotide was end-labeled with $\left[\alpha-{ }^{35} \mathrm{~S}\right] \mathrm{dATP}(1200 \mathrm{Ci} / \mathrm{mmol}$; DuPont NEN, Hounslow, UK) in a 30:1 molar ratio of radiolabeled ATP/oligonucleotide using terminal deoxynucleotidyl transferase (Promega, Southampton, UK) as described previously (Wisden and Morris, 1994). Specific activity of the ${ }^{35} \mathrm{~S}$-labeled probe was between $2.0 \times 10^{5}$ and $3.0 \times 10^{5}$ $\mathrm{dpm} / \mu \mathrm{l}$ probe.

Hybridizations were performed essentially as described by Wisden and Morris (1994). To define nonspecific hybridization, adjacent slidemounted sections were incubated with radiolabeled $\gamma$ PKC oligonucleotide probe in the presence of an excess $(100 \times)$ concentration of unlabeled oligonucleotide probe. After hybridization, sections were exposed to Kodak BioMax x-ray film for 1-2 weeks. After obtaining appropriate $\mathrm{x}$-ray film exposures, we dipped sections in $\mathrm{K} 5$ photographic emulsion (Ilford). Sections were exposed for 5-10 weeks at $4^{\circ} \mathrm{C}$ before development and counterstaining with $0.01 \%$ thionine.

Silver grain density was assessed in discrete neuronal populations using OpenLab imaging software (ImproVision). Coordinates were as follows: anterior cingulate $(\mathrm{Cg} 1)$ and prelimbic $(\mathrm{PrL})$ cortical pyramidal neurons, bregma $+3.5 \mathrm{~mm}$; nucleus accumbens core and shell, bregma $+1.7 \mathrm{~mm}$; central nucleus of the amygdala $(\mathrm{CeN})$ neurons, bregma $-2.0 \mathrm{~mm}$; CA1 pyramidal neurons and dentate gyrus (dg) granule cells, bregma -3.3 $\mathrm{mm}$; lateral (LA) and basal (B) amygdala pyramidal neurons, bregma $-3.0 \mathrm{~mm}$; VTA neurons, bregma $-6.1 \mathrm{~mm}$ (Paxinos and Watson, 1997) (Fig. 1). Briefly, silver grains (total and nonspecific) were counted over sufficient randomly selected neurons from each region for each animal such that the SE of the counts for any region was $<10 \%$ of the population mean (typically 24 cells). In each case, cells were selected from at least three separate sections that were right-left side counterbalanced. Then a specific grain count was calculated for each region by subtracting total and nonspecific counts. All neurons in the 10 regions that we studied showed constitutive levels of $\gamma$ PKC expression. The mean silver grain count in each region for each animal was then divided by the mean count in that region for the Paired group $\times 100$ to give a standardized grain count for each group. Results were standardized to the common Paired group to control for differences in absolute grain densities across several in situ hybridization repetitions. The analysis of silver grain density was made by an investigator who was blind to the treatment regimen of the individual sections. Standardized results were analyzed by ANOVA, and individual post hoc comparisons were made using Tukey's test for pairwise comparisons.

\section{RESULTS}

\section{Acquisition of intravenous cocaine self-administration}

The number of days for the Paired and Unpaired groups to reach the criterion for drug lever discrimination ranged from 9 to $12 \mathrm{~d}$. Active (drug) and inactive lever responses during the first (Fig. 2a) and last (Fig. 2b) 9 d of intravenous self-administration for each experimental group were analyzed. The use of backward analysis in which the data were time-locked to each rat that was self-administering drug and had reached training criterion permits the comparison of lever-pressing behavior between the four experimental groups immediately before the test phase, regardless of the length of training. There was a significant Group $\times$ Lever $\times$ Day interaction over the first $\left[F_{(24,304)}=3.007 ; \epsilon=\right.$ $0.501 ; p<0.01]$ and last $\left[F_{(24,304)}=2.076 ; \epsilon=0.522 ; p<0.05\right] 9 \mathrm{~d}$ of training. In addition, there was a significant Group $\times$ Lever interaction over the first $\left[F_{(3,38)}=15.974 ; p<0.001\right]$ and last 

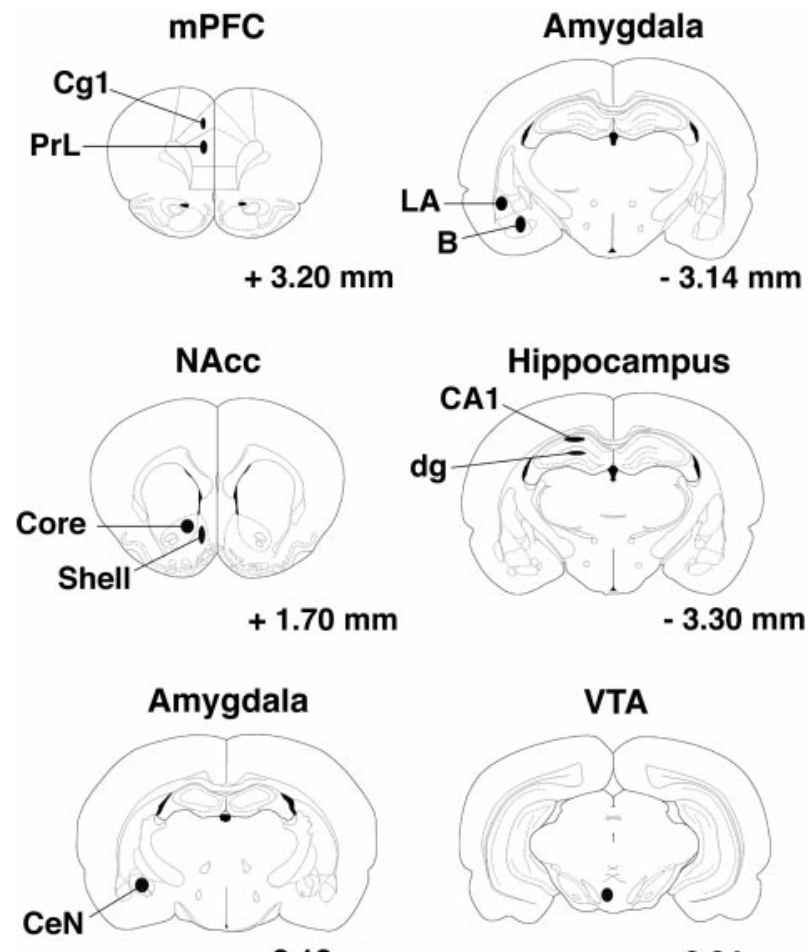

Figure 1. Schematic representation of the brain regions targeted for grain density measurement. Bilateral measurements in the mPFC $(C g 1$ and $\operatorname{Pr} L$ ), NAcc (Core and Shell), amygdala ( $C e N, L A$, and $B$ ), hippocampus ( $d g$ and $C A 1$ ), and VTA were made as indicated. Coronal sections are marked "+" for anterior and "-" for posterior to bregma (Paxinos and Watson, 1997).

$\left[F_{(3,38)}=16.728 ; p<0.001\right] 9 \mathrm{~d}$ of training. Individual analysis for each group of active and inactive presses over the first $9 \mathrm{~d}$ of training revealed an effect of day for the Paired $\left[F_{(8,136)}=4.302\right.$; $\epsilon=0.492 ; p<0.01]$ and Unpaired $\left[F_{(8,40)}=8.494 ; \epsilon=0.886 ; p<\right.$ $0.001]$ groups but not for the Pavlovian $\left[F_{(8,88)}=1.327 ; \epsilon=0.184\right.$; $p=0.283]$ and Saline $\left[F_{(8,40)}=1.311 ; p=0.266\right]$ groups. These results reflect the appearance of discriminated lever-pressing behavior in the Paired and Unpaired groups with the progressive increase in responding on the active lever during training.

Post hoc analysis revealed that in the last $9 \mathrm{~d}$ of training, although there were differences in the discriminated leverresponding behavior between the Paired group and the Pavlovian ( $p<0.001$, Sidak) or Saline $(p<0.01$, Sidak) groups, there was no significant difference between the Paired and Unpaired groups ( $p=0.828$, Sidak). Therefore, there were no consequences of pairing a tone rather than a light with cocaine SA during training either on the degree of lever discrimination or on the vigor of lever-pressing behavior in the final days of training. Furthermore, there were no differences in the total number of cocaine inf usions in those groups (Unpaired, Paired, and Pavlovian) of rats that received cocaine (Fig. $2 c)\left[F_{(2,33)}=0.693 ; p=0.507\right.$, Tukey's test].

\section{Regional $\gamma$ PKC expression after exposure to a cocaine-associated cue}

Analysis of the regional density of silver grains as a measure of $\gamma$ PKC expression $2 \mathrm{hr}$ after exposure of the experimental animals to a light stimulus on the test day resulted in a significant Group $\times$ Region interaction $\left[F_{(27,372)}=2.976 ; p<0.001\right]$, reflecting different levels of $\gamma$ PKC expression between both the experimental groups
$\left[F_{(3,372)}=2.787 ; p<0.05\right]$ and the distinct regions $\left[F_{(9,372)}=\right.$ 4.098; $p<0.001]$.

Within the amygdala, individual analysis for each region of $\gamma$ PKC expression revealed that there was a group effect on grain density in the lateral nucleus (Fig. $3 a)\left[F_{(3,38)}=7.834 ; p<0.001\right]$ that reflected an increase in $\gamma$ PKC expression in the Pavlovian group compared with the Saline controls (Fig. 3b,c) and also with the Unpaired and Paired groups. The effect of group on $\gamma$ PKC expression in the basal amygdala (Fig. $3 d$ ) $\left[F_{(3,38)}=2.995 ; p<\right.$ $0.05]$ and the $\mathrm{CeN}$ (Fig. $3 e)\left[F_{(3,38)}=8.009 ; p<0.001\right]$ resulted from an increase in expression in the Paired and Pavlovian groups compared with the Saline group. In addition, $\gamma$ PKC expression in the $\mathrm{CeN}$ in the Paired and Pavlovian groups was elevated with respect to that measured in the Unpaired group.

There were differences in the density of silver grains between the experimental groups in the Cg1 (Fig. $4 a)\left[F_{(3,37)}=7.246 ; p<\right.$ 0.001] and also in the PrL (Fig. $4 b)\left[F_{(3,37)}=2.833 ; p<0.05\right]$ region of the rat frontal cortex. In the $\mathrm{Cg} 1$ area, this was attributable to a decrease in $\gamma \mathrm{PKC}$ expression in the Pavlovian group in comparison with the Saline, Unpaired, and Paired groups. In the PrL, both the Pavlovian (Fig. 4d) and Paired groups also showed decreased $\gamma$ PKC expression with respect to the Saline control group (Fig. 4c).

No changes in $\gamma \mathrm{PKC}$ expression were seen in the CA1 region of the hippocampus (Fig. $5 a)\left[F_{(3,35)}=0.174 ; p=0.913\right]$ or $\mathrm{dg}$ (Fig. $5 b)\left[F_{(3,35)}=0.262 ; p=0.852\right]$.

There was an effect of group in the core region of the NAcc (Fig. $6 a)\left[F_{(3,38)}=7.867 ; p<0.001\right]$ but not in the NAcc shell (Fig. 6b) $\left[F_{(3,38)}=1.178 ; p=0.331\right]$ or in the VTA (Fig. 6c) $\left[F_{(3,38)}=1.316 ; p=0.283\right]$. The significant effect of the group in the NAcc core resulted from an increase in grain density in the Unpaired and Paired groups, compared with the Saline control group.

\section{DISCUSSION}

Presentation of a light CS that had been associated previously with self-administered cocaine produced discrete, regional alterations in the expression of the $\gamma$ isoform of PKC. Three general patterns of altered gene response were evident (Table 2). (1) The first pattern was dependent on whether rats had received the cocaine infusion initially and the CS contingent on a behavioral response (Paired group) or whether they were administered drug-CS pairings noncontingently (Pavlovian group). (2) Although increased $\gamma$ PKC expression was measured within the amygdala in both the Paired and Pavlovian groups, decreased expression was seen within areas of the mPFC. Thus, both groups showed increased $\gamma$ PKC expression in the B and $\mathrm{CeN}$ amygdala and decreased $\gamma$ PKC expression in the PrL cortex. However, the Pavlovian group showed additional changes in $\gamma$ PKC mRNA levels in the NAcc core, LA of the amygdala, and anterior cingulate cortex. (3) In marked contrast to the increased $\gamma$ PKC expression within the amygdala, no changes in its expression within the hippocampus were seen in any group on exposure to cocaine cues. This result is in accord with data supporting a role for the amygdala, but not the hippocampus, in conditioning to discrete cues (Selden et al., 1991; Holland and Gallagher, 1998; LeDoux, 2000). By contrast, the hippocampus has been suggested to underlie conditioning to contextual and spatial cues (Eichenbaum et al., 1999; Holland and Bouton, 1999; Fanselow, 2000; Maren and Holt, 2000). Moreover, the acquisition of an association between a neutral discrete cue and food reward in both Pavlovian and instrumental learning tasks has been shown not to 
a

First 9 Days Training

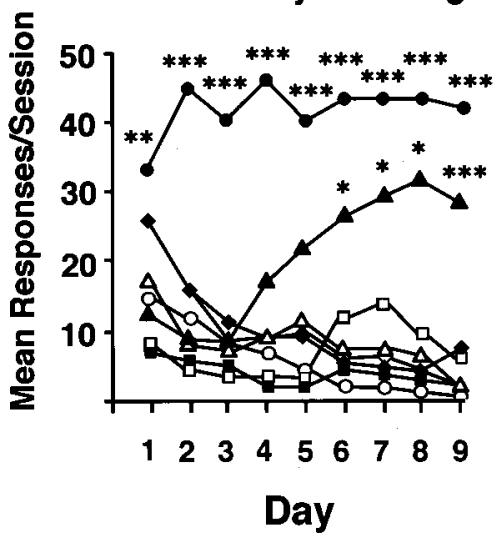

b

\section{Last 9 Days Training}

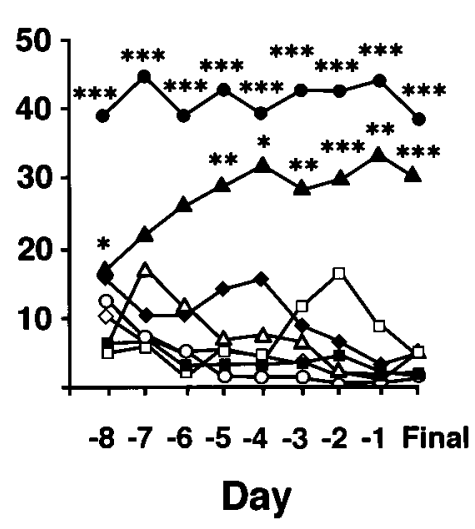

Levers

Active - Paired

Active - Pavlovian
Inactive

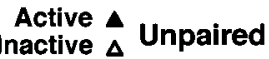

Active

Inactive $\diamond$ Saline
C

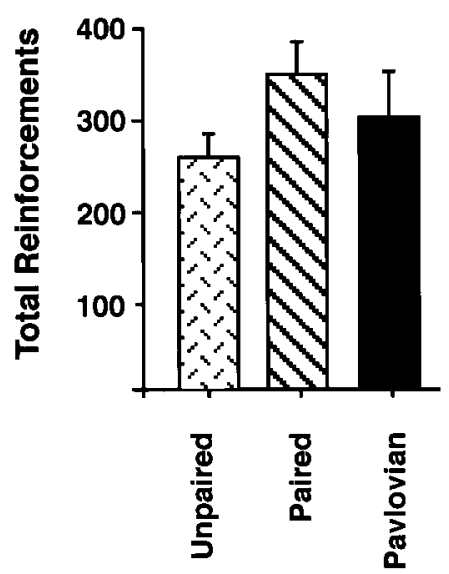

Figure 2. Acquisition of intravenous cocaine SA. $a, b$, The mean number of responses on the active (cocaine or saline SA,) or inactive (no programmed consequence) levers in the $2 \mathrm{hr}$ training sessions in the first $9 \mathrm{~d}$ of training $(a)$ or the last $9 \mathrm{~d}$ of training $(b) . c$, The total number of cocaine $(0.25 \mathrm{mg}$ base $/ 0.1 \mathrm{ml}$ saline) infusions in rats self-administering (Unpaired and Paired groups) or receiving yoked administrations (Pavlovian) of the drug. ${ }^{*} p<$ $0.05,{ }^{* *} p<0.01,{ }^{* * *} p<0.001$, in comparison with the responses at the inactive lever; Sidak's test. Error bars indicate SEM.

depend on hippocampal processing (Baldwin et al., 2000; Parkinson et al., 2000a).

The alterations in $\gamma \mathrm{PKC}$ expression in response to the conditioned light stimulus were selective to its predictive association with cocaine because, with the exception of the NAcc core (see below), $\gamma$ PKC expression was unchanged in rats that had been trained to self-administer cocaine not paired with a light CS (Unpaired group). The genetic responses were not attributable to nonspecific neuronal adaptations to the chronic administration of cocaine because no differences were measured between the Saline control group and the cocaine-experienced Unpaired group. Moreover, the experimental design determined that all cocaineexperienced groups received a similar number of drug inf usions. All rats had been presented with the light stimulus during training, regardless of whether it was a CS, so that the effects of the novelty of presentation of the light on the test day were equated across groups. Therefore, the changes in $\gamma \mathrm{PKC}$ expression in the instrumentally and Pavlovian-conditioned rats were specific to retrieval of CS-associated memories.

\section{$\gamma$ PKC as a cellular activity marker}

Several cellular imaging studies have investigated the expression of the immediate early gene $c$-fos in response to environments associated with cocaine administration (Brown et al., 1992; Crawford et al., 1995; Franklin and Druhan, 2000; Neisewander et al., 2000). Although each study reported conditioned changes in c-Fos protein, there were some differences in the neuroanatomical responses that may be at least partly attributed to methodological differences. However, regions of the mPFC were engaged consistently by the cocaine-associated environments and also activated by a discrete, cocaine-associated cue in this study, as measured by changes in $\gamma$ PKC expression. Furthermore, a priming injection of cocaine also induced c-fos in the anterior cingulate cortex but only in rats that had undergone conditioning (Neisewander et al., 2000), again suggesting that the anterior cingulate cortex may form part of the neural circuitry that encodes a representation of the effects of cocaine.
Imaging studies in human cocaine users have revealed that exposure to discrete, cocaine-associated stimuli results in increased metabolic activity in frontal cortical regions, including the anterior cingulate and dorsolateral prefrontal cortex and the amygdala, activations that were correlated with self-reports of craving for cocaine (Grant et al., 1996; Maas et al., 1998; Childress et al., 1999). Although the NAcc in these human brain imaging studies may not have been resolved anatomically, the concordance of the present, cellular imaging data with such studies of human addicts indicates the face validity of using in situ hybridization of $\gamma$ PKC mRNA as a tool to investigate at the cellular and systems levels the neural basis of associative mechanisms critical to addictive behavior.

\section{Processing the CS in the amygdala}

The cocaine-associated light stimulus consistently increased $\gamma$ $\mathrm{PKC}$ expression in the $\mathrm{CeN}$ and $\mathrm{B}$. However, the increase in the LA was seen only in rats having undergone purely Pavlovian pairings of cocaine and light CS.

There is significant support for a role of the $\mathrm{CeN}$ in processing Pavlovian stimulus-reward associations (Kapp et al., 1979; Gallagher et al., 1990; Davis, 1992; Parkinson et al., 2000b) and for the B and LA (the BLA complex) in mediating the affective motivational properties of reward-associated cues (Hatfield et al., 1996; Everitt et al., 2000), including cocaine-associated cues (Whitelaw et al., 1996; Meil and See, 1997). The selective induction of $\gamma$ PKC mRNA in the CeN and B of the Paired and Pavlovian groups may index the reactivation of these two associations but additionally may reflect the role of the $\mathrm{CeN}$ to influence conditioned somatic, autonomic, and endocrine responses on exposure to the drug cue (Everitt et al., 1999).

Few studies have investigated a functional role for the LA independent of the $\mathrm{B}$, and as a consequence there is a paucity of data that allow a dissociation of LA and B function. However, specific excitotoxic lesions of the LA that left the B and CeN intact were reported to prevent the acquisition of a conditioned place preference for amphetamine, leading to the suggestion that 
a
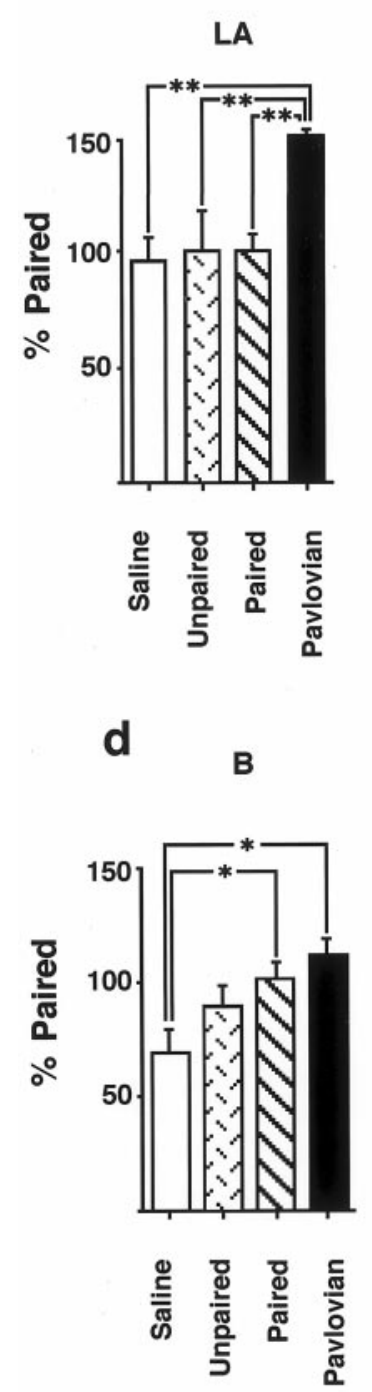

b

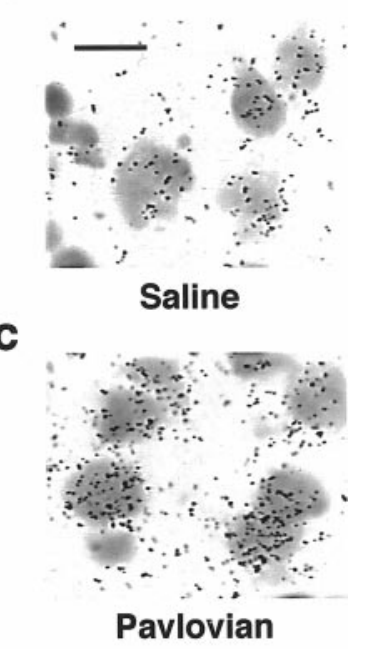

e

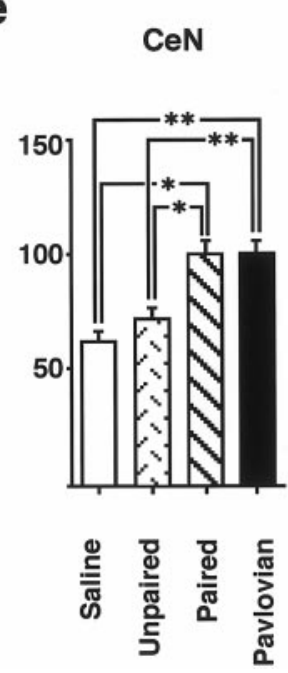

Figure 3. CS-induced $\gamma$ PKC expression in the amygdala. $a$, The percentage change in the density of silver grains $2 \mathrm{hr}$ after light stimulus presentation in neurons of the lateral amygdala in rats trained with noncontingent light $\mathrm{CS}$-cocaine (Pavlovian group) or light $\mathrm{CS}$-saline (Saline group) pairings and in rats trained to self-administer cocaine associated with a tone CS (Unpaired group) relative to the density measured in rats trained to self-administer cocaine paired with the light CS (Paired group). $b, c$, Representative photomicrographs showing the individual silver grains over thionine-counterstained LA amygdala neurons in a section from rats from Saline $(b)$ and Pavlovian $(c)$ groups. Scale bar, $15 \mu \mathrm{m} . d, e$, The percentage change in the density of silver grains 2 $\mathrm{hr}$ after light stimulus presentation in neurons of the basal $(d)$ and $\mathrm{CeN}$ (e) subregions of the amygdala. ${ }^{*} p<0.05,{ }^{* *} p<0.01$; Tukey's test. Error bars indicate SEM.

the LA is a possible neural site of association of cues with the primary rewarding effect of amphetamine (Hiroi and White, 1991). Similarly, the LA has been shown to be the site of storage of associations formed between discrete auditory stimuli and an aversive unconditioned stimulus during Pavlovian fear conditioning (Fanselow and LeDoux, 1999).

If the increase in $\gamma$ PKC expression in the LA does indeed reflect the stimulus-reward association, then an increase would have been expected in the Paired as well as in the Pavlovian group, but this was not the case. There may be two kinds of

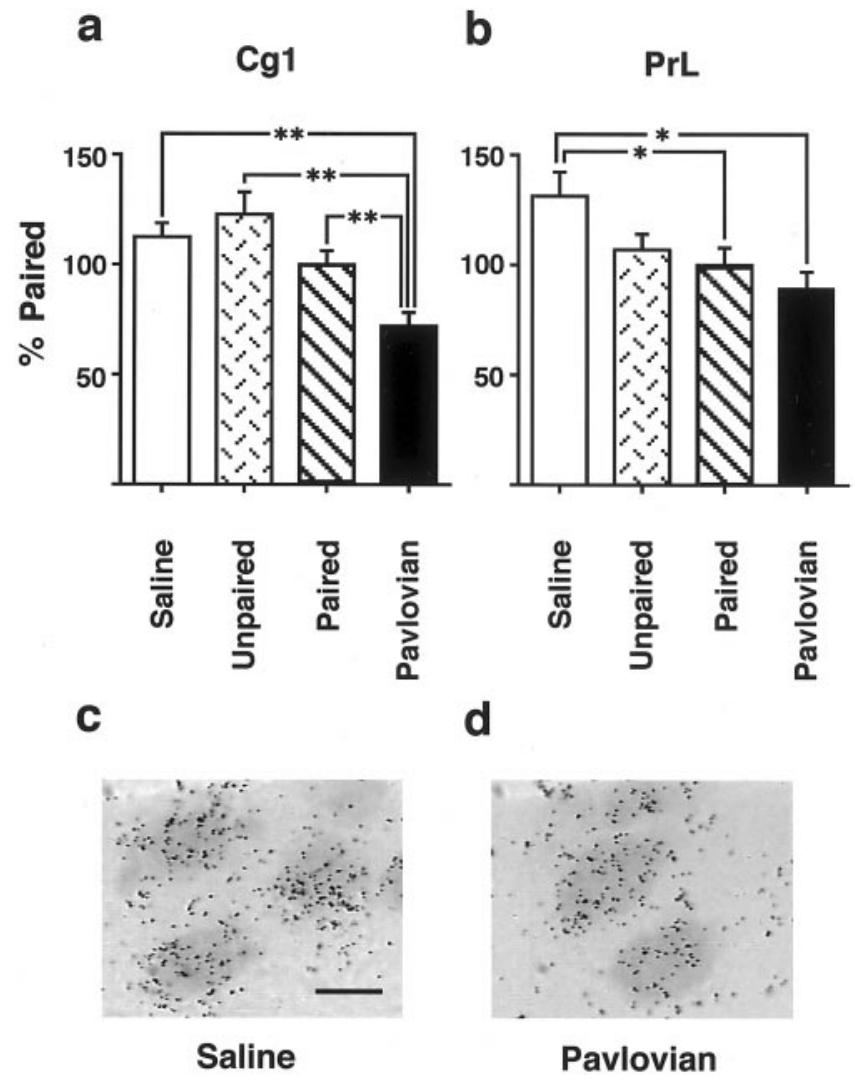

Figure 4. CS-induced $\gamma$ PKC expression in the medial prefrontal cortex. $a, b$, The neuronal density of silver grains in $\mathrm{Cg} 1(a)$ or PrL $(b)$ regions measured $2 \mathrm{hr}$ after presentation of a light stimulus to rats trained to self-administer cocaine and paired either with a light CS (Paired group) or tone CS (Unpaired group), or to rats that had received noncontingent cocaine and light CS (Pavlovian group) or saline and light CS (Saline group) administrations during training. The results are shown relative to the density measured in the Paired group (100\%). * $p<0.05,{ }^{*} p<0.01$; Tukey's test. Error bars indicate SEM. $c, d$, Representative photomicrographs showing the individual silver grains over thionine-counterstained PrL neurons in a section from rats from Saline $(c)$ and Pavlovian $(d)$ groups. Scale bar, $15 \mu \mathrm{m}$.

explanation for this dissociation in responses in amygdala nuclei. The first concerns the fact that stimulants, such as cocaine, have both appetitive and aversive effects (Spealman, 1979; Ettenberg and Geist, 1991), especially when administered noncontingently (Everitt et al., 1999). Given the strong association between the LA and aversive (fear) conditioning (Fanselow and LeDoux, 1999), this may explain in part the selective activation of the LA by cues associated with cocaine given noncontingently, because it is under such conditions that aversive effects may predominate (Everitt et al., 1999). The second explanation is that for the Paired group, the CS may selectively engage neural circuitry involving the B and NAcc core to mediate drug-seeking because it retrieves information about the CS associated with the instrumental contingency, and this process might be independent of the LA.

\section{Processing the CS in the medial prefrontal frontal cortex}

In rats, there is evidence that the anterior cingulate and prelimbic cortices subserve dissociable functions. Anterior cingulate cortex lesions, but not mPFC lesions that encompass PrL cortex, disrupt Pavlovian stimulus-reward associations, whereas more rostral $\mathrm{mPFC}$ lesions result selectively in attentional deficits (Bussey et 
a

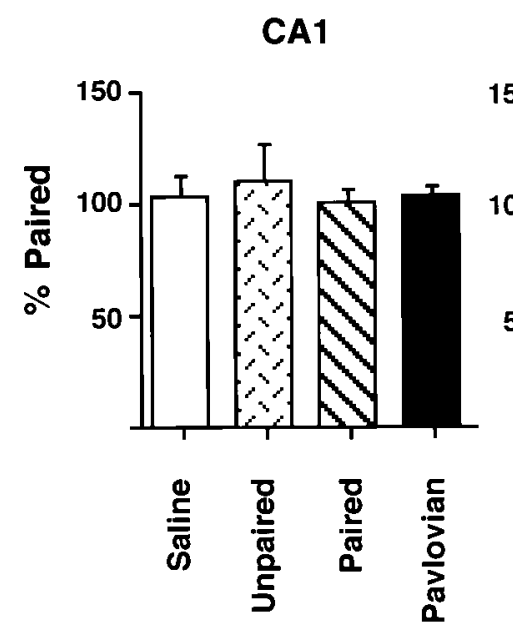

b

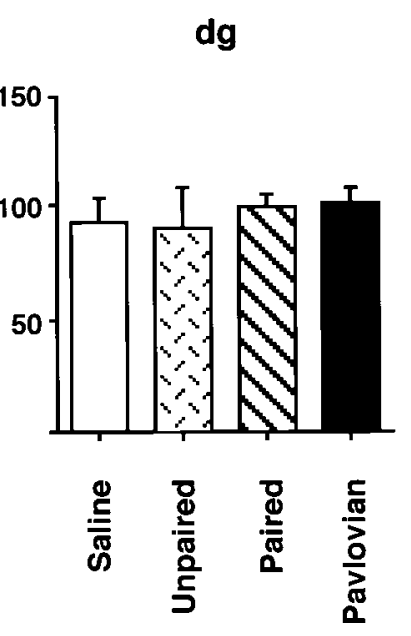

Figure 5. CS-induced $\gamma$ PKC expression in the hippocampus. $a, b$, The expression of $\gamma$ PKC in CA1 $(a)$ and $\mathrm{dg}(b)$ neurons in rats trained to self-administer cocaine paired with a light CS (Paired group) or a tone CS (Unpaired group) or in rats trained with noncontingent administration of cocaine and light CS (Pavlovian group) or saline and light CS (Saline group). The results are presented as silver grain density relative to the Paired group (100\%). Error bars indicate SEM.

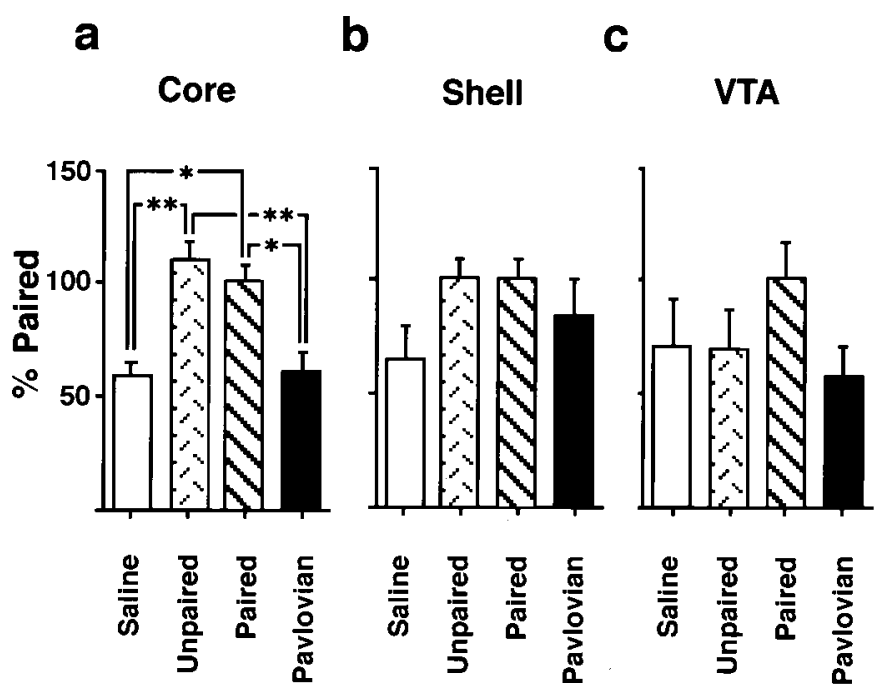

Figure 6. CS-induced $\gamma$ PKC expression in mesoaccumbal DA system. The density of silver grains, standardized to the number of grains per neuron, measured in animals self-administering cocaine and receiving paired light CS (Paired group) in the core of the NAcc (a), the shell of the NAcc $(b)$, and VTA $2 \mathrm{hr}$ after presentation of a light stimulus $(c)$ in groups of rats that, during training, received either yoked noncontingent presentations of the light CS and cocaine (Pavlovian group) or saline (Saline group), or rats that had self-administered cocaine paired with an auditory tone (Unpaired group). ${ }^{*} p<0.05,{ }^{* *} p<0.01$; Tukey's test. Error bars indicate SEM.

al., 1997a,b). Moreover, rostral anterior frontal cortex neurons (encompassing the $\mathrm{Cg} 1$ region studied here) respond selectively to stimuli predictive of food reward (Takenouchi et al., 1999). In the context of addictive behavior, not only is the anterior cingulate cortex activated on exposure to cocaine cues, but selective lesions of the anterior cingulate or prelimbic cortices prevent the control over cocaine-seeking behavior by drug-associated cues (Weissenborn et al., 1997).

Table 2. Summary of regional changes in $\gamma$ PKC expression

\begin{tabular}{lcccc} 
& Group & & & \\
\cline { 2 - 5 } Region & Saline & Unpaired & Paired & Pavlovian \\
\hline Core & 0 & $\uparrow$ & $\uparrow$ & 0 \\
Shell & 0 & 0 & 0 & 0 \\
VTA & 0 & 0 & 0 & 0 \\
CA1 & 0 & 0 & 0 & 0 \\
dg & 0 & 0 & 0 & 0 \\
Cg1 & 0 & 0 & 0 & $\downarrow$ \\
PrL & 0 & 0 & $\downarrow$ & $\downarrow$ \\
LA & 0 & 0 & 0 & $\uparrow$ \\
B & 0 & 0 & $\uparrow$ & $\uparrow$ \\
CeN & 0 & 0 & $\uparrow$ & $\uparrow$
\end{tabular}

$\overline{\uparrow, \text { Increased expression; } \downarrow \text {, decreased expression; } 0 \text {, no change in expression with }}$ respect to the Saline group.

Conditioned stimuli generally produce decreases in the activity of neurons in the anterior cingulate cortex and the PrL regions, whether predictive of a natural food reward or an aversive footshock (Garcia et al., 1999; Takenouchi et al., 1999). Although there is no clear evidence that the direction of a change in gene expression is directly correlated with neuronal activity, the decrease in expression of $\gamma \mathrm{PKC}$ in medial prefrontal cortical regions in response to the cocaine-associated cue shown here may reflect a similar conditioned decrease in neuronal activity.

\section{Processing the CS in the nucleus accumbens and ventral tegmental area}

Expression of $\gamma \mathrm{PKC}$ was increased in the NAcc core in both the Paired and Unpaired groups. This stands in marked contrast to those changes found in the amygdala and mPFC in which alterations were seen only in the Paired and Pavlovian groups and therefore related specifically to the cue that was predictive of cocaine. There are two possible explanations for this result. First, the genomic response in the NAcc core may not be specific to the associative recall of the drug cue and instead reflects some other sensory-dependent process. Second, molecular neuroadaptations in the NAcc in response to repeated cocaine administration are well established (Nestler and Aghajanian, 1997), and thus the large number of cocaine infusions received during training for the Paired, Unpaired, and Pavlovian groups may have induced an increased basal expression of $\gamma$ PKC in the NAcc core. Indeed, acute intravenous cocaine does increase $\gamma$ PKC expression within the NAcc (our unpublished observations). Therefore, presentation of the cocaine CS may have led to decreased $\gamma$ PKC expression in the NAcc core selectively in the Pavlovian group, just as decreased $\gamma$ PKC mRNA levels were seen in the $\mathrm{Cg} 1$ for this group. Presumably, genomic responses in the NAcc core are determined by patterns of input from limbic cortical areas, and because the $\mathrm{Cg} 1$ projects richly to the core (Parkinson et al., 2000a), the decreased response seen here in the Pavlovian group may reflect coordinated responses by these areas.

Lesions of the NAcc apparently do not disrupt measures of instrumental learning, such as the knowledge of the contingency between a rewarded outcome and the action to gain the reward (Balleine and Killcross, 1994). However, selective lesions of the NAcc core, but not the shell, do abolish both the acquisition and the performance of a purely Pavlovian learning task, autoshaping (Parkinson et al., 1999, 2000a). Moreover, lesions of the core made after learning a Pavlovian association between a CS and 
food reward do not prevent the subsequent acquisition of a new response with conditioned reinforcement (Parkinson et al., 2000a). These data suggest a dissociation in the role for the NAcc, especially the core region, in the neural mechanism underlying Pavlovian and instrumental learning. In addition, they suggest that the CS-induced decrease in $\gamma$ PKC expression in the NAcc core in the Pavlovian, but not in the Paired, group that initially had been responding instrumentally for cocaine reflects the selective engagement or activation of the core during the processing of Pavlovian-conditioned stimuli.

The null effect of the CS presentation on gene expression in the largely dopaminergic neurons of the VTA does not necessarily indicate that activity in this region remained unaltered under these conditions. Indeed, increased electrophysiological activity in the dopaminergic neurons of the VTA has been shown to occur in response to the presentation of stimuli associated with reward (Ljungberg et al., 1992). Our results simply indicate that this possibly enhanced neuronal activity is not associated with increases in $\gamma$ PKC expression. Indeed, it is only patterns of neuronal activity that induce long-term changes in synaptic strength which correlate with changes in $\gamma$ PKC expression (Thomas et al., 1994). It remains a possibility that although the VTA itself may not be a site of associative synaptic plasticity involving $\gamma \mathrm{PKC}$, activity there may mediate plasticity in other brain regions such as the striatum and prefrontal cortex (Schultz and Dickinson, 2000).

\section{Synthesis}

The oppositional nature of the changes in $\gamma$ PKC expression in the amygdala and $\mathrm{Cg} 1$ and $\mathrm{PrL}$ regions of the mPFC observed in this study on presentation of a drug-associated CS closely corresponds with the changes in BLA-induced prefrontal cortical activity seen in electrophysiological studies. Although presentation of reward-related stimuli increases firing responses in neurons of the BLA complex (Muramoto et al., 1993; Ono et al., 1995; Pratt and Mizumori, 1998), stimulation of glutamatergic BLA afferents elicits excitatory and inhibitory responses in the mPFC, with the latter responses predominating (Perez-Jaranay and Vives, 1991).

Individual neurons of the medial NAcc core and shell receive convergent glutamatergic afferents from the amygdala, hippocampus, and mPFC (O’Donnell and Grace, 1995; Finch, 1996). The outcome of simultaneous stimulation of two sources of glutamatergic afferents in terms of neuronal firing of these NAcc neurons is complex (Pennartz et al., 1994; O’Donnell and Grace, 1995; Mulder et al., 1998). The stimulation of BLA neurons elicits firing of NAcc neurons, whereas activation of hippocampal afferents does not reliably initiate NAcc neuronal firing but does cause NAcc neurons to switch to an "active" state that permits activation by mPFC inputs (O’Donnell and Grace, 1995). The processing of discrete conditioned cues apparently does not involve hippocampal activation (Burns et al., 1993; LeDoux, 2000), and $\gamma$ PKC expression was not increased in the hippocampus by the CS in the present study. Thus, the pattern of $\gamma$ PKC expression induced by the cocaine-associated CS in this study indicates that motivationally salient, discrete stimuli are processed by specific elements of limbic-cortical-ventral striatopallidal circuitry. However, the precise ways in which interactions between the amygdala and the medial prefrontal cortical areas determine the activity of, and expression of $\gamma$ PKC within, accumbens neurons remains to be determined. It should also be considered that the changes we observed in $\gamma$ PKC expression may reflect plasticity-related processes initiated on stimulus-cued retrieval. Thus, it has been demonstrated that Pavlovian associations require a protein synthesis-dependent "reconsolidation" (Nader et al., 2000). This reconsolidation may involve plasticity-related processes (Przybyslawski and Sara, 1997), and the selective changes in the regional expression of the plasticity-related gene $\gamma$ PKC in those groups in which the light stimulus was associated with cocaine seen in the present study may form part of the molecular mechanism underlying the lasting storage of this Pavlovian association. Furthermore, the associative storage of input patterns to the NAcc may be mediated by the strengthening sets of prefrontal and amygdala inputs. Indeed, LTP-like associative plasticity processes have been described in the BLA, anterior cingulate cortex, and NAcc (Pennartz et al., 1993; Jay et al., 1995; Maren and Fanselow, 1995).

\section{Conclusion}

Exposure of rats to a discrete cocaine-associated stimulus in the absence of both the drug and the ability to self-administer it altered $\gamma$ PKC expression in the NAcc and its cortical afferent structures. The expression of $\gamma \mathrm{PKC}$ was selective to those rats in which there was a predictive stimulus-cocaine relationship. The pattern of expression was dependent on whether, during training, the rats self-administered cocaine or received it noncontingently. Although changes in $\gamma \mathrm{PKC}$ expression were common to these groups, additional changes were observed in the NAcc core, LA, and $\mathrm{Cg} 1$ in rats having received explicitly Pavlovian pairings of noncontingent drug and CS. Further investigations of gene expression patterns in response to cocaine-associated stimuli presented as contingent on lever pressing, i.e., as conditioned reinforcers, may clarify the mechanisms within cortical-ventral striatopallidal circuits engaged by the dissociable consequences of Pavlovian conditioning (Everitt et al., 1999; Parkinson et al., 2000a,b).

\section{REFERENCES}

Abeliovich A, Chen C, Goga Y, Silva AJ, Stevens CF, Tonegawa S (1993a) Modified hippocampal long-term potentiation in PKC $\gamma$ mutant mice. Cell 75:1253-1262.

Abeliovich A, Paylor R, Chen C, Kim JJ, Wehner JM, Tonegawa S (1993b) PKC $\gamma$ mutant mice exhibit mild deficits in spatial and contextual learning. Cell 75:1263-1271.

Abraham WC, Mason SE, Demmer J, Williams JM, Richardson CL, Tate WP, Lawlor P, Dragunow M (1993) Correlations between immediate early gene induction and the persistence of long-term potentiation. Neuroscience 56:717-727.

Arroyo M, Markou A, Robbins TW, Everitt BJ (1998) Acquisition, maintenance and reinstatement of intravenous cocaine selfadministration under a second-order schedule of reinforcement in rats: effects of conditioned cues and continuous access to cocaine. Psychopharmacology (Berl) 140:331-344.

Baldwin AE, Holahan MR, Sadeghian K, Kelley AE (2000) N-Methyl$\mathrm{D}$-aspartate-dependent plasticity within a distributed corticostriatal network mediates appetitve instrumental learning. Behav Neurosci 114:84-98.

Balleine BW, Dickinson A (1998) Goal directed instrumental action: contingency and incentive learning and their cortical substrates. Neuropharmacology 37:407-419.

Balleine BW, Killcross S (1994) Effects of ibotenic acid lesions of the nucleus accumbens on instrumental action. Behav Brain Res 65:181-193.

Berke JD, Hyman SE (2000) Addiction, dopamine and the molecular mechanisms of memory. Neuron 25:515-532.

Brown EE, Robertson GS, Fibiger HC (1992) Evidence for conditional neuronal activation following exposure to a cocaine-paired environment: role of forebrain limbic structures. J Neurosci 12:4112-4121.

Burns LH, Robbins TW, Everitt BJ (1993) Differential effects of excitotoxic lesions of the basolateral amygdala, ventral subiculum and medial prefrontal cortex on responding with conditioned reinforcement and locomotor activity potentiated by intra-accumbens infusions of D-amphetamine. Behav Brain Res 55:167-183.

Burns LH, Everitt BJ, Robbins TW (1994) Intra-amygdala infusion of the $N$-methyl-D-aspartate receptor antagonist AP5 impairs the acquisition but not the performance of discriminated approach to an appetitive CS. Behav Neural Biol 61:242-250. 
Bussey TJ, Everitt BJ, Robbins TW (1997a) Dissociable effects of cingulate and medial frontal cortex lesions on stimulus-reward learning using a novel Pavlovian autoshaping procedure for the rat: implications for the neurobiology of emotion. Behav Neurosci 111:908-919.

Bussey TJ, Muir JL, Everitt BJ, Robbins TW (1997b) Triple dissociation of anterior cingulate, posterior cingulate and medial frontal cortices on visual discrimination tasks using a touchscreen testing procedure for the rat. Behav Neurosci 111:920-936.

Caine SB, Lintz R, Koob GF (1993) Intravenous drug selfadministration techniques in animals. In: Behavioural neuroscience: a practical approach, Vol II (Shagal A, ed), pp. 117-143. New York: Oxford UP.

Childress AR, Ehrman RN, Rohsenow D, Robbins SJ, O'Brien CP (1993) Classically conditioned factors in drug dependence. In: Comprehensive textbook of substance abuse (Lowinson J, Luiz P, Millman RB, Langard JG, eds), pp 56-69. Baltimore: Williams \& Wilkins.

Childress AR, Mozley PD, McElgin W, Fitzgerald J, Reivich MD, O'Brien CP (1999) Limbic activation during cue-induced cocaine craving. Am J Psychiatry 156:11-18.

Cornish JL, Kalivas PW (2000) Glutamate transmission in the nucleus accumbens mediates relapse in cocaine addiction. J Neurosci 20:RC89 (1-5).

Crawford CA, McDougall SA, Bolanos CA, Hall S, Berger SP (1995) The effects of the kappa agonist U-50,488 on cocaine-induced conditioned and unconditioned behaviors and Fos immunoreactivity. Psychopharmacology (Berl) 120:392-399.

Davis HP, Squire LR (1984) Protein synthesis and memory: a review. Psychol Bull 96:518-559.

Davis M (1992) The role of the amygdala in conditioned fear. In: The amygdala: neurobiological aspects of emotion, memory and mental dysfunction (Aggleton J, ed), pp 255-306. New York: Wiley.

Dickinson A, Balleine BW (1994) Motivational control of instrumental behaviour. Anim Learn Behav 22:1-18.

Douma BRK, Van der Zee EA, Luiten PGM (1998) Translocation of protein kinase $\mathrm{C} \gamma$ occurs during the early phase of acquisition for food rewarded spatial learning. Behav Neurosci 112:496-501.

Dragunow M, Faull R (1989) The use of c-fos as a metabolic marker in neuronal pathway tracing. J Neurosci Methods 29:261-265.

Eichenbaum H, Dudchenko P, Wood E, Shapiro M, Tanila H (1999) The hippocampus, memory, and place cells: is it spatial memory or a memory space? Neuron 23:209-226.

Ettenberg A, Geist TD (1991) Animal model for investigating the axiogenic effects of self-administered cocaine. Psychopharmacology (Berl) 103:445-461.

Everitt BJ, Parkinson JA, Olmstead MC, Arroyo M, Robledo P, Robbins TW (1999) Associative processes in addiction and reward. The role of amygdala-ventral striatal systems. Ann NY Acad Sci 877:412-438.

Everitt BJ, Cardinal RN, Hall J, Parkinson JA, Robbins TW (2000) Differential involvement of amygdala subsystems in appetitive conditioning and drug addiction. In: The amygdala: a functional analysis (Aggleton JP, ed), pp 353-390. Oxford: Oxford UP.

Fanselow MS (2000) Contextual fear, gestalt memories, and the hippocampus. Behav Brain Res 110:73-81.

Fanselow MS, LeDoux JE (1999) Why we think plasticity underlying Pavlovian fear conditioning occurs in the basolateral amygdala. Neuron 23:229-232.

Finch DM (1996) Neurophysiology of converging synaptic inputs from the rat prefrontal cortex, amygdala, midline thalamus and hippocampal formation onto single neurons of the caudate/putamen and nucleus accumbens. Hippocampus 6:495-512.

Franklin TR, Druhan JP (2000) Expression of fos-related antigens in the nucleus accumbens and associated regions following exposure to a cocaine-paired environment. Eur J Neurosci 12:2097-2106.

Gallagher M, Graham PW, Holland PC (1990) The amygdala central nucleus and appetitive Pavlovian conditioning: lesions impair one class of conditioned performance. J Neurosci 10:1906-1911.

Garcia R, Vouimba R-M, Baudry M, Thompson R (1999) The amygdala modulates prefrontal cortex activity relative to conditioned fear. Nature 402:294-296.

Gawin FH (1991) Cocaine addiction: psychology and neurophysiology. Science 251:1580-1586.

Grant S, London ED, Newlin DB, Villemange VL, Lui X, Cortoreggi C, Philips RL, Kimes AS, Margolin A (1996) Activation of memory circuits during cue-elicited cocaine craving. Proc Natl Acad Sci USA 93:12040-12045.

Graybiel AM, Moratalla R, Robertson HA (1990) Amphetamine and cocaine induce drug-specific activation of the c-fos gene in striosomematrix compartments and limbic subdivisions of the striatum. Proc Natl Acad Sci USA 87:6912-6916.

Hatfield T, Han JS, Conley M, Gallagher M, Holland P (1996) Neurotoxic lesions of the basolateral, but not central amygdala interfere with Pavlovian second-order conditioning and reinforcer devaluation effects. J Neurosci 16:5256-5265.

Hiroi N, White NM (1991) The lateral nucleus of the amygdala mediates expression of amphetamine-produced conditioned place preference. J Neurosci 11:2107-2116.

Holland PC, Bouton ME (1999) Hippocampus and context in classical conditioning. Curr Opin Neurobiol 9:195-202.

Holland PC, Gallagher M (1998) Amygdala circuitry in attentional and representational processes. Trends Cogn Sci 3:65-73.

Hope BT, Nye HE, Kelz MB, Self DW, Iadarola MJ, Nakabeppu Y, Duman RS, Nestler EJ (1994) Induction of a long-lasting AP-1 complex composed of altered Fos-like proteins in brain by chronic cocaine and other chronic treatments. Neuron 13:1235-1244.

Jay TM, Burette F, Laroche S (1995) NMDA receptor-dependent longterm potentiation in the hippocampal afferent fibre system to the prefrontal cortex in the rat. Eur J Neurosci 7:247-250.

Kapp BS, Frysinger RC, Gallagher M, Haselton JR (1979) Amygdala central nucleus lesions: effect on heart rate conditioning in the rabbit. Physiol Behav 23:1109-1117.

Kelley AE, Smith-Roe S, Holahan MR (1997) Response-reinforcement learning is dependent on NMDA receptor activation in the nucleus accumbens core. Proc Natl Acad Sci USA 94:12174-12179.

LeDoux JE (2000) Emotion circuits in the brain. Annu Rev Neurosci 23:155-184

Ljungberg T, Apicella P, Schultz W (1992) Responses of monkey dopamine neurons during learning of behavioral reactions. J Neurophysiol 67:145-163.

Maas LC, Lukas SE, Kaufman MJ, Weiss RD, Daniels SL, Rogers VW, Kukes TJ, Renshaw PF (1998) Functional magnetic resonance imaging of human brain activation during cue-induced cocaine craving. Am J Psychiatry 155:124-126.

Maren S, Fanselow MS (1995) Synaptic plasticity in the basolateral amygdala induced by hippocampal formation stimulation in vivo. J Neurosci 15:7548-7564

Maren S, Holt W (2000) The hippocampus and contextual memory retrieval in Pavlovian conditioning. Behav Brain Res 110:97-108.

Meil WM, See RE (1997) Lesions of the basolateral amygdala abolish the ability of drug-associated cues to reinstate responding during withdrawal from self-administered cocaine. Behav Brain Res 87:139-148.

Miserendino MJD, Sananes CB, Melia KR, Davis M (1990) Blocking of acquisition but not expression of conditioned fear-potentiated startle by NMDA antagonists in the amygdala. Nature 345:716-718.

Morris RG, Anderson E, Lynch GS, Baudry M (1986) Selective impairment of learning and blockade of long-term potentiation by an $N$-methyl-D-aspartate receptor antagonist, AP5. Nature 319:774-776.

Mulder AB, Hopenpil MG, Lopes da Silva FH (1998) Electrophysiology of the hippocampal and amygdaloid projections to the nucleus accumbens of the rat: convergence, segregation, and interaction of inputs. J Neurosci 18:5095-5102

Muramoto K, Ono T, Nishijo H, Fukuda M (1993) Rat amygdaloid neuron responses during auditory discrimination. Neuroscience 52:621-636.

Nader K, Schafe GE, LeDoux JE (2000) Fear memories require protein synthesis in the amygdala for reconsolidation after retrieval. Nature 406:722-726.

Neisewander JL, Baker DA, Fuchs RA, Tran-Nguyen LTL, Palmer A, Marshall JF (2000) Fos protein expression and cocaine-seeking behavior in rats after exposure to a cocaine self-administration environment. J Neurosci 20:798-805.

Nestler EJ, Aghajanian GK (1997) Molecular and cellular basis of addiction. Science 278:58-63.

Nishizuka Y (1988) The molecular heterogeneity of protein kinase C and its implications for cellular regulation. Nature 334:661-665.

O'Brien CP, Childress AR, McLellen AT, Ehrman R (1992) Classical conditioning in drug dependent humans. Ann NY Acad Sci 654:400-415

O’Donnell P, Grace AA (1995) Synaptic interactions among excitatory afferents to nucleus accumbens neurons: hippocampal gating of prefrontal cortical input. J Neurosci 15:3622-3639.

Ono T, Nishijo H, Uwano T (1995) Amygdala role in conditioned associative learning. Prog Neurobiol 46:401-422.

Ono Y, Fujii T, Igarashi K, Kikkawa U, Ogita K, Nishizuka Y (1988) Nucleotide sequences of cDNAs for alpha and gamma subspecies of rat brain protein kinase C. Nucleic Acids Res 16:5199-5200.

Parkinson JA, Olmstead MC, Burns LH, Robbins TW, Everitt BJ (1999) Dissociation in effects of the nucleus accumbens core and shell on appetitive Pavlovian approach behavior and the potentiation of conditioned reinforcement and locomotor activity by D-amphetamine. J Neurosci 19:2401-2411.

Parkinson JA, Willoughby PJ, Robbins TW, Everitt BJ (2000a) Disconnection of the anterior cingulate cortex and nucleus accumbens core impairs Pavlovian approach behaviour: further evidence for limbic cortico-ventral striatopallidal systems. Behav Neurosci 114:42-63.

Parkinson JA, Robbins TW, Everitt BJ (2000b) Dissociable role of the central and basolateral amygdala in appetitive emotional learning. Eur J Neurosci 12:405-413.

Paxinos G, Watson C (1997) The rat brain in stereotaxic coordinates, Ed 3. San Diego: Academic. 
zPennartz CM, Ameerun RF, Groenewegen HJ, Lopes da Silva F (1993) Synaptic plasticity in an in vitro slice preparation of the rat nucleus accumbens. Eur J Neurosci 5:107-117.

Pennartz CM, Groenewegen HJ, Lopes da Silva FH (1994) The nucleus accumbens as a complex of functionally distinct neuronal ensembles: an integration of behavioural, electrophysiological and anatomical data. Prog Neurobiol 42:719-761.

Perez-Jaranay JM, Vives F (1991) Electrophysiological study of the response of medial prefrontal cortex neurons to stimulation of the basolateral nucleus of the amygdala in the rat. Brain Res 564:97-101.

Pratt WE, Mizumori SJ (1998) Characteristics of basolateral amygdala neuronal firing on a spatial memory task involving differential reward. Behav Neurosci 112:554-570.

Przybyslawski J, Sara SJ (1997) Reconsolidation of memory after its reactivation. Behav Brain Res 84:241-246.

Roberts DC, Corcoran ME, Fibiger HC (1977) On the role of ascending catecholaminergic systems in intravenous self-administration of cocaine. Pharmacol Biochem Behav 6:615-620.

Schultz W, Dickinson A (2000) Neuronal coding of prediction errors. Annu Rev Neurosci 23:473-500.

Selden NRW, Everitt BJ, Jarrard LE, Robbins TW (1991) Complementary roles for the amygdala and hippocampus in aversive-conditioning to explicit and contextual cues. Neuroscience 42:335-350.

Spealman RD (1979) Behaviour maintained by termination of a schedule of self-administered cocaine. Science 15:1231-1233.

Stewart J, de Wit H, Eikelboom R (1984) Role of unconditioned and conditioned drug effects in the self-administration of opiates and stimulants. Psychol Rev 91:251-268.

Takenouchi K, Nishijo H, Uwano T, Takigawa M, Ono T (1999) Emotional and behavioural correlates of the anterior cingulate cortex during associative learning in rats. Neuroscience 93:1271-1287.
Thomas KL, Laroche S, Errington ML, Bliss TVP, Hunt SP (1994) Spatial and temporal changes in signal transduction pathways during LTP. Neuron 13:737-745.

Tiffany ST (1990) A cognitive model of drug urges and drug-use behavior: role of automatic and non-automatic processes. Psychol Rev 97:147-168.

Van der Zee EA, Compaan JC, De Boer M, Luiten PGM (1992) Changes in PKC $\gamma$ immunoreactivity in mouse hippocampus induced by spatial discrimination learning. J Neurosci 12:4808-4815.

Van der Zee EA, Kronfrost-Collins MA, Maizels ET, Hunzicker-Dunn M, Disterhoft JF (1997) $\gamma$ Isofrom selective changes in PKCimmunoreactivity after trace eyeblink conditioning in the rabbit hippocampus. Hippocampus 7:271-285.

Weissenborn R, Robbins TW, Everitt BJ (1997) Effects of medial prefrontal or anterior cingulate cortex lesions on responding for cocaine under fixed-ratio and second-order schedules of reinforcement in rats. Psychopharmacology (Berl) 134:242-257.

Whitelaw RB, Markou A, Robbins TW, Everitt BJ (1996) Excitotoxic lesions of the basolateral amygdala impair the acquisition of cocaineseeking behavior under a second-order schedule of reinforcement. Psychopharmacology (Berl) 127:213-224.

Wisden W, Morris BJ (1994) In situ hybridisation with synthetic oligonucleotide probes. In: In situ hybridisation protocols for the brain (Wisden W, Morris BJ, eds), pp 9-34. London: Academic.

Wise RA, Bozarth MA (1987) A psychomotor stimulant theory of addiction. Psychol Rev 94:469-492.

Worley PF, Bhat RV, Baraban JM, Erickson CA, McNaughton BL, Barnes CM (1993) Thresholds for synaptic activation of transcription factors in hippocampus: correlation with long-term enhancement. J Neurosci 13:4776-4786. 